\title{
Coeliac disease among children in Kuwait: difficulties in diagnosis and management
}

\author{
F A KHUFFASH, M H BARAKAT, A A SHALTOUT, S S FARWANA, \\ M S ADNANI, AND M F TUNGEKAR
}

\begin{abstract}
From the Departments of Paediatrics, Medicine and Pathology in Kuwait University, and the Department of Paediatrics in Mubarak El-Kabeer Hospital, Kuwait
\end{abstract}

SUMMARY Twenty children with coeliac disease were diagnosed over a five year period in an area with 10000-12000 births per year. The average annual incidence was 1:3000 births. All children presented with severe symptoms and rickets was not uncommon $(25 \%)$. Mean age at onset of symptoms was 38 months (range 6-120) and 72 months at the time of diagnosis (range 13-192), with a mean delay of 34 months. No cases were diagnosed during infancy. The difficulties in the differentiation of coeliac disease from the more common causes of chronic diarrhoea, and problems with diagnosis and management are discussed.

The fact that coeliac disease (CD) is not confined to Caucasians is now well established. ${ }^{1-6}$ Its prevalence in developing countries may be underestimated, however, because of the lack of diagnostic resources and the overwhelming number of children with the postgastroenteritis syndromes. ${ }^{-\infty}$ Differentiation of $\mathrm{CD}$ from these syndromes is difficult because of similar clinical presentation and, occasionally, similar histological findings. ${ }^{910}$

The occurrence of $\mathrm{CD}$ in Kuwait has been the subject of one report. ${ }^{6}$ We now report our experience with the disease over a five year period, and aim at highlighting the difficulties met in the suspicion and the diagnosis of $\mathrm{CD}$ and the problems encountered during follow up in Kuwait, a country with a subtropical location that still shares with the developing countries many of their health problems.

\footnotetext{
Methods

PATIENTS

The study involves 20 children with $C D$ diagnosed during the period between April 1980 and March 1985. The catchment area is populated by 350000 , about two thirds of whom are Arab expatriates, with about 12000 annual births.

Address for correspondence: Dr Faisal A Khuffash. Department of Paediatrics. Faculty of Medicine. Kuwait University, PO Box No 2492.3. 13110. Safat Kuwait.

Received for publication 30 April, 1987
}

On the suspicion of $\mathrm{CD}$, a detailed clinical and dietary history was recorded. Blood samples were obtained for a full blood count, serum iron, immunoglobulin electrophoresis and a complete SMAC-20 profile. Sweat chloride level was estimated for all patients, and folate level, bone age and thyroid functions for some. The one hour D-xylose level was estimated after a standard dose of $1 \mathrm{~g} / \mathrm{kg}$. The stools were repeatedly examined for parasites and cultured for intestinal pathogens. Multiple intestinal biopsies were obtained from the distal part of the duodenum through peroral fibreoptic endoscopy as previously described by us." A duodenal aspirate was taken at the same time to be examined for Giardia. The histological grading was assessed according to the classification used by Lee and Tomer. ${ }^{12}$ The biopsy specimens were also examined for Giardia.

At the start of elimination of gluten from the diet, supplements of vitamins $A$ and $D$, folic acid and iron were given during the first six to 12 months. Children were seen regularly every one to three months and their growth velocity was estimated using a reference standard. ${ }^{13}$

A second biopsy was obtained after 12-18 months (so far accepted in 12 children). Challenge with gluten could be arranged in six children and was patient inspired in two more. The child was allowed gradually increasing amounts of wheat products until he was on non-restricted diet in two to three weeks. The third biopsy was done for only five patients. 


\section{Results}

Of the 20 children studied there were seven boys and 13 girls. Two of these children were monozygotic twin girls $\mathrm{s}^{\mathrm{t}}$ and four were female siblings from a large family with 11 offsprings. The mean age at the time of diagnosis was 72 months (range 13-192) and at the onset of symptoms was 38 months (range 6-120), with a mean delay of 38 months.

The average annual incidence of $\mathrm{CD}$ in the area studied was 1:3000 births. Thirteen children were of Palestinian origin (incidence 1:2400), three were Kuwaities (incidence 1:6500). Two were Syrians, one from Egypt and one from Yemen.

Most patients presented with severe symptoms (Table 1) and 16 of them were repeatedly admitted to other hospitals with the clinical diagnosis of milk intolerance. All children had chronic diarrhoea and growth retardation, and $80 \%$ had wasting and abdominal distension. Rickets were particularly common $(25 \%)$ and a number of children $(25 \%)$ were admitted with exacerbation by severe watery diarrhoea, dehydration and hypokalaemia (coeliac
Table 1 Clinical manifestations in 20 children with coeliac disease

\begin{tabular}{lrr}
\hline Manifestation & $n$ & $\%$ \\
\hline Chronic diarrhoca & 20 & $(100 \%)$ \\
Slow growth & 20 & $(100 \%)$ \\
Abdominal distension & 16 & $(80 \%)$ \\
Mood changes & 5 & $(75 \%)$ \\
Coeliac crises & 5 & $(25 \%)$ \\
Rickets & 5 & $(25 \%)$ \\
\hline
\end{tabular}

crises). Episodes of constipation were reported in six children.

The relevant biochemical and histological abnormalities are shown in Table 2 and Figure 1(a). Seven children who underwent biopsy on suspicion of $C D$ were excluded because of finding another aetiology. Four had Giardia and three had milk intolerance after salmonellosis (two patients) and Campylobacter infection (one patient). All seven children responded dramatically to appropriate therapy.

Acceleration of growth was most impressive during

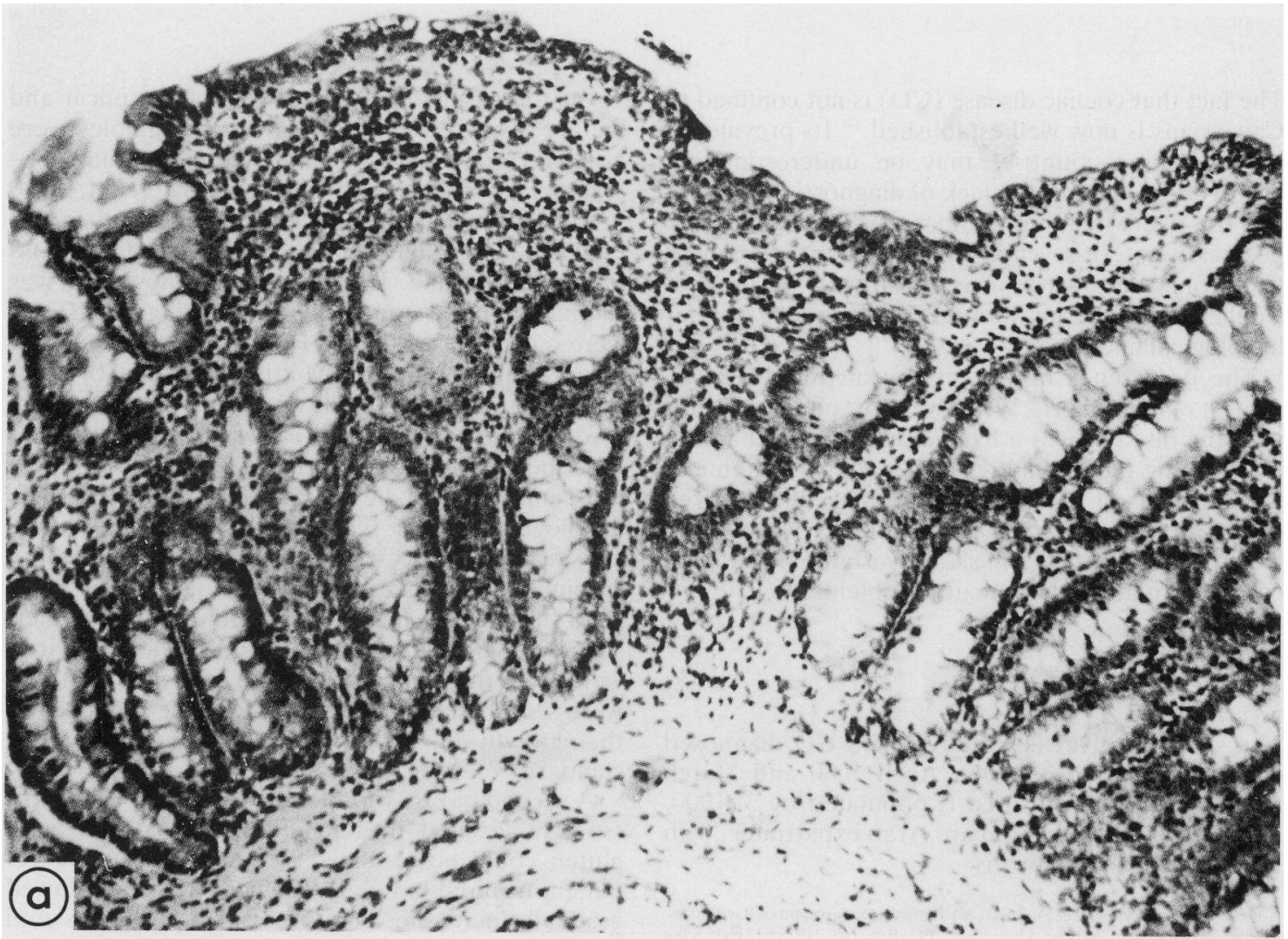

Fig. 1 Histological appearance of a series of intestinal biopsy specimens from one representative A rab child with coeliac disease. (a) On admission: subtotal villous atrophy with dense infiltrate of the lamina propria by lymphocytes. $H \& E$. 
Table 2 Histological and biochemical abnormalities in 20 children with coeliac disease

\begin{tabular}{lrrr}
\hline & $n$. & \multicolumn{2}{l}{$n$. } \\
Abnormality & Tested & Positive & $\%$ \\
\hline Anacmia & 20 & 13 & $(65 \%)$ \\
Hypochromia & 20 & 16 & $(80 \%)$ \\
Low folatc & 6 & 4 & $(66 \%)$ \\
D-xylose $(<20 \mathrm{mg} / 10() \mathrm{ml})$ & 19 & 18 & $(94 \%)$ \\
Intestinal changes & 20 & 20 & $(100 \%)$ \\
$\quad$ partial villous atrophy & & 4 & $(20 \%)$ \\
subtotal villous atrophy & & 16 & $(80 \%)$ \\
\hline
\end{tabular}

the first year of gluten elimination: the weight velocity averaged 2.7 times the normal value (range $1 \cdot 2-4 \cdot 1)$ and the height velocity averaged 1.8 times normal (range 1.4-2.5). Compliance with gluten elimination was very difficult after the first year particularly in school children: our supply of gluten free flour was very patchy and we found great difficulties in supplying sweets and sandwiches for the school child.
Of the 12 children in whom a second biopsy could be obtained there was a histological remission in seven (Fig. 1(b)). The other five showed only mild to marginal improvement and all patients admitted to marked irregularity of gluten restriction.

There was a clinical and histological relapse in all of the five children who underwent a third biopsy following gluten challenge (Fig. 1(c)). There was a clinical relapse in the other three but the family refused the third biopsy.

\section{Discussion}

In view of the high prevalence of postgastroenteritis syndromes in Kuwait, ${ }^{78}$ we decided to strictly adhere to the widely accepted criteria for the diagnosis of CD. ${ }^{1+15}$ With the relative ease and safety of our biopsy procedure," we should be able to confirm the diagnosis in most patients with suspected CD.

The incidence of CD in Kuwait may be compared with that in the West of Ireland during the late $50 \mathrm{~s} .{ }^{\text {in }}$ The late $70 \mathrm{~s}$, however, witnessed a sharp fall in the

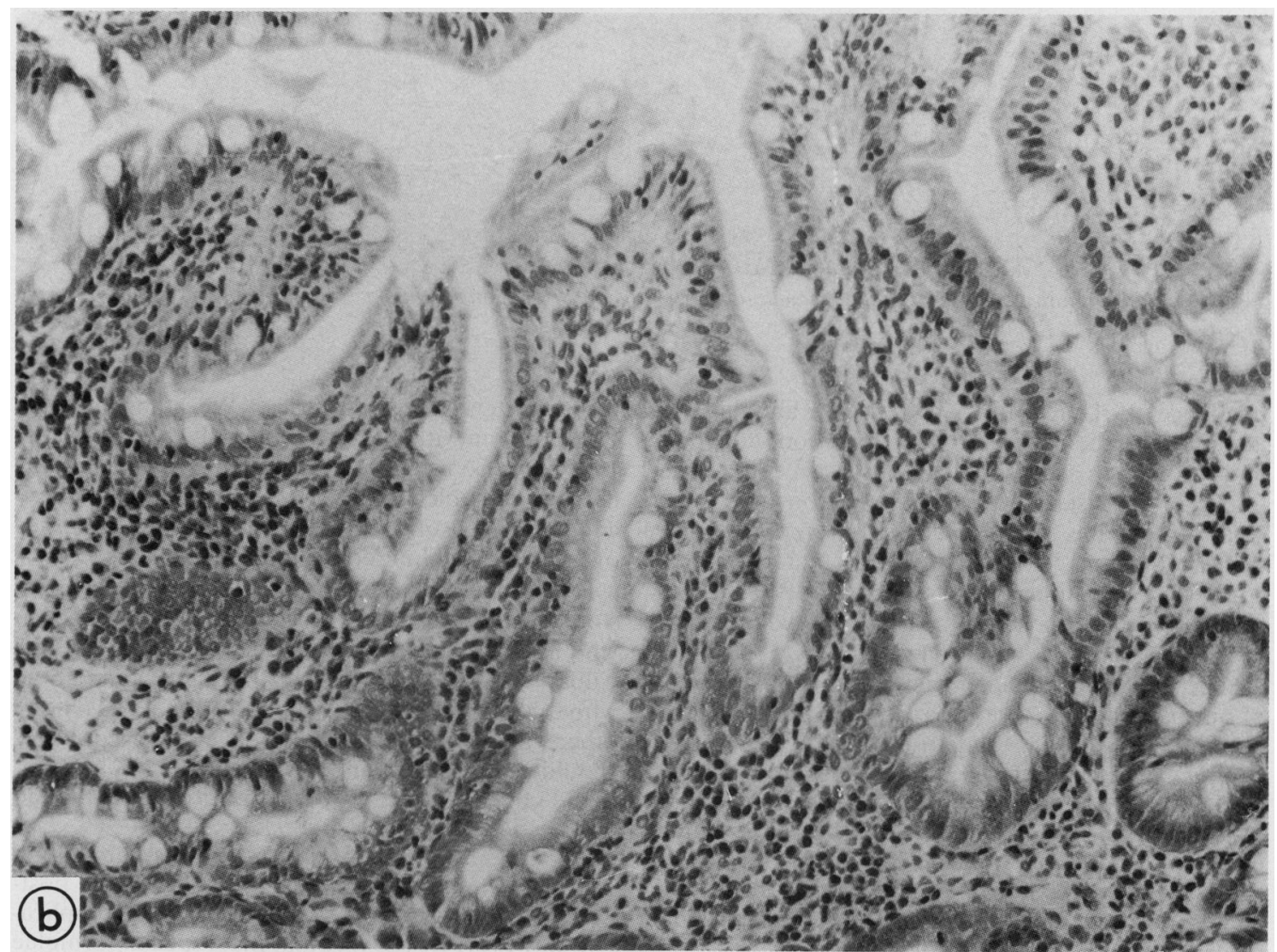

Fig. 1(b) Twelve months after gluten elimination: improvement of villous height and regression of the lymphocytic infiltrate. $H \& E$. 


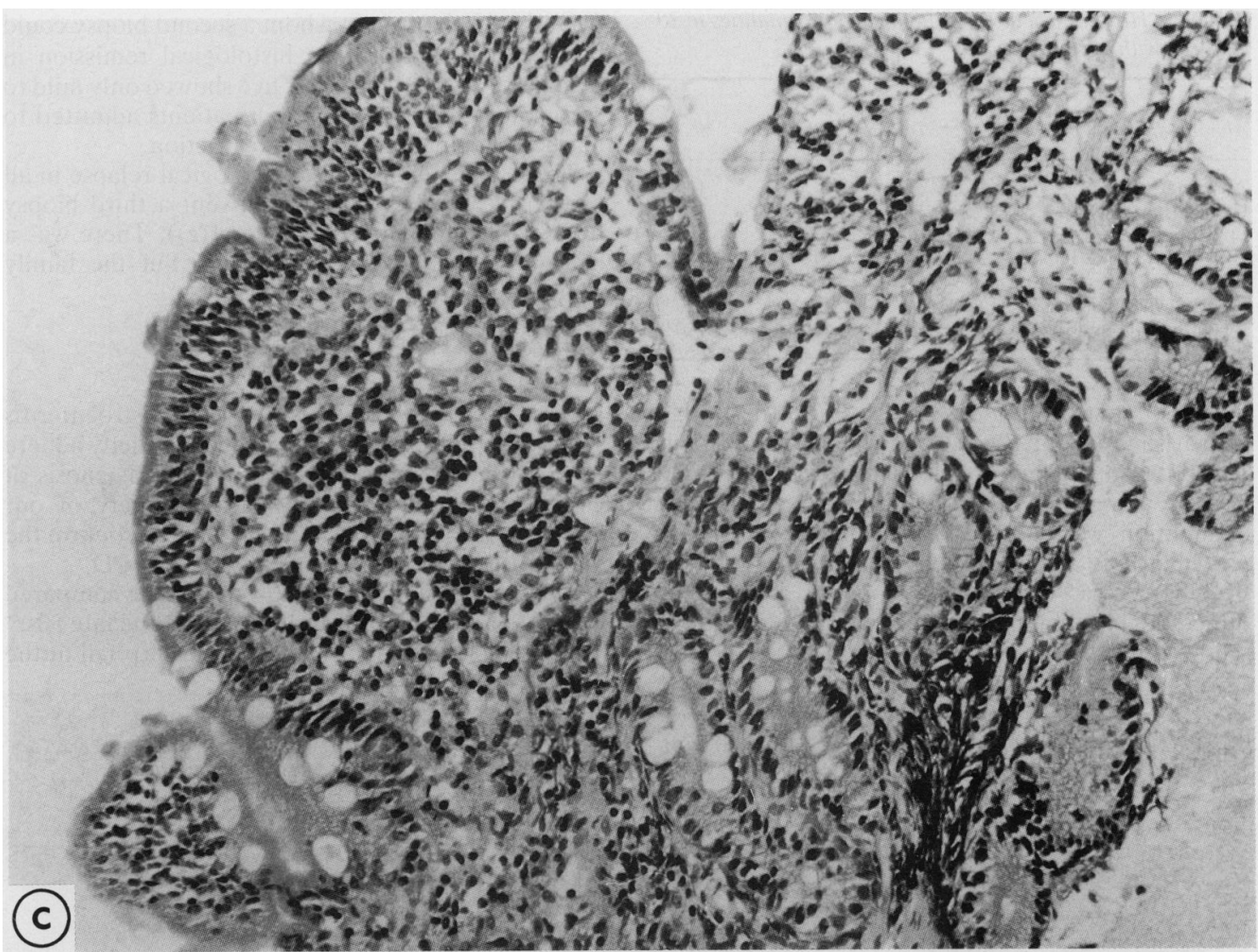

Fig. 1(c) Four months after gluten challenge: villous shortening and broadening with hypercellularity of the lamina propria. $H \& E$.

incidence of $\mathrm{CD}$ in Western countries ${ }^{1718}$ and this was attributed to the delay in the introduction of cereals and to the increased practice of breast feeding. The impact of increased wheat consumption on the expression of $C D$ has been discussed in reports from developing areas. ${ }^{1+5}$ It is noteworthy that $\mathrm{CD}$ in this study was three times more common in Palestinians with large wheat consumption than in Kuwaities with a high consumption of rice. The figure of 1:3000 may also be an underestimate in view of the fact that most of our patients had severe symptoms (Table 1). The marked delay in the diagnosis (mean 34 months) compares poorly with a $90 \%$ rate of diagnosis during infancy. ${ }^{18}$ The repeated previous admissions is another disturbing feature suggesting that $C D$ is being missed or, at best, the diagnosis delayed until adult life. Extending the indications for biopsy to include children with more subtle manifestations has improved the rate of detection of $\mathrm{CD} .^{19}$

The contribution of $C D$ to the number of children with chronic diarrhoea is minimal in Kuwait ${ }^{7 \times 21}$ and in other developing countries. ${ }^{5}$ We admit about a 1000 children with diarrhoea annually, of whom over 100 have chronic diarrhoea and other manifestations indistinguishable from $C D$. Subjecting all these children to absorption tests and intestinal biopsies overwhelms the limited diagnostic resources. This is certainly true for less prosperous countries with similar health problems. In a study of 519 children who had intestinal biopsy on the suspicion of $C D$ in Cuba, ${ }^{5}$ only $50(8.8 \%)$ showed findings compatible with the diagnosis. The relative paucity of $\mathrm{CD}$ among other causes of diarrhoea in developing countries should call for a high index of suspicion of $C D$, and, at the same time, for proper utilisation of the limited diagnostic resources.

The dramatic offset of diarrhoea after elimination of the offending milk is characteristic of the postgastroenteritis syndromes. ${ }^{17 \times}$ This issue is complicated, however, by the fact that most special formulae used for this purpose are gluten free, "1 and that many children with $C D$ have milk intolerance." Further- 
more, the flat mucosa characteristic of CD can also be seen in the postgastroenteritis syndromes." These difficulties are particularly relevant to paediatricians in developing countries. We think, however, that careful longterm follow up is a reasonable safeguard against missing $\mathrm{CD}$ or over referrals to the expensive work up. The situation can certainly be reviewed at a later date..$^{15}$

The great difficulties we met with compliance to gluten restriction were anticipated. It was initially difficult to convince parents that wheat bread (called 'the survival' in the local language) is the cause of the child's severe symptoms. It was possible, however, to achieve compliance in all cases after improvement was shown, when the child becomes lively and playful after prolonged misery. In a community poorly informed about $\mathrm{CD}$, extra patience and efforts are needed to ensure optimum care for the family and the child.

Coeliac disease is probably more common in Kuwait than in many developed countries. ${ }^{1718}$ It is, however, still far outnumbered by other causes of diarrhoea. Paediatricians working in developing countries have to balance between a high index of suspicion and over utilisation of resources. Careful clinical follow up of all patients with chronic diarrhoea is probably a reasonable attitude towards both underdiagnosis and over referrals.

\section{References}

1 Walia BNS, Sidhu JK, Tandon BN, Ghai OP, Bhargava $\mathrm{S}$. Coeliac disease in North Indian children. Br Med J 1966; ii: 1233-4.

2 Nelson R, McNeish AS, Anderson CM. Coeliac disease in children of Asian immigrants. Lancet 1973; i: 348-50.

3 Al-Hassany M. Coeliac disease in Iraqi children. J Trop Pediatr 1975; 21 : 178-9.

4 Suliman GI. Coeliac disease in Sudanese children. Gut 1978; 19: 121-5.
5 Rabassa EB, Sagaro E, Fragoso T, Castaneda C, Gra B. Coeliac disease in Cuban children. Arch Dis Child 1980; 56: 128-31.

6 Khuffash FA, Barakat MH, Majeed HA, White AG, Beseda AJ. Coeliac disease in monozygotic twin girls. Synchronous presentation. Gut 1984; 25: 1009-12.

7 Shaltout AA, Khuffash FA. Pattern of chronic diarrhoea among children in Kuwait (under preparation).

8 Khuffash FA, Majeed HA, Sethi SK, Al-Nakib W. Gastroenteritis in a regional hospital in Kuwait: some aspects of the disease. Ann Trop Paediatr 1982; 2: 123-8.

9 Anderson CM, Gracey M, Burke V. Coeliac disease. Some still controversial aspects. Arch Dis Child 1972; 47: 292-8.

10 Lebenthal E, Branski D. Childhood coeliac disease - a reappraisal. J Pediatr 1981; 98: 681-90.

11 Barakat MH, Ali SM, Badawi AR, et al. Peroral endoscopic biopsy in infants and children. Acta Paediatr Scand 1983; 72: 563-9.

12 Lee FD, Tomer PG. Biopsy pathology of the small intestine. Chapman and Hall. London, 1980: pp 97-104.

13 Tanner JM. Physical growth and development. In: Forfar JD, Arneil GC, eds. Textbook of Paediatrics. 2nd edition. Churchill-Livingstone, 1978.

14 Meeuwisse GW. Diagnostic criteria in coeliac disease. Acta Paediatr Scand 1970; 59: 461-3.

15 Dodge JA. Gluten intolerance, gluten enteropathy and coeliac disease. Arch Dis Child 1980; 55: 143-5.

16 Mylotte M, Egan-Mitchell B, McCarthy CF, McNichol B. Incidence of coeliac disease in the West of Ireland. Br Med J 1979; i: 703-5.

17 Littlewood JM, Crollick AJ, Richards IDG. Coeliac disease is disappearing [letter]. Lancet 1980; ii: 1359.

18 Simila S, Kokkonen J, Voulokka P, Kouvalainen K. Childhood coeliac disease. Lancet 1981; i: 494-5.

19 Cacciari E, Salardi S, Lazzari R, et al. Short stature and coeliac disease: a relationship to consider even in patients with nogastrointestinal manifestations. J Pediatr 1983; 103: 708-11.

20 Khuffash FA, Majeed HA. Basic epidemiological aspects of acute gastroenteritis in a regional hospital in Kuwait. Ann Trop Paediatr 1984; 4: 113-5. 